\title{
Accounting for seasonality in a soil moisture change detection algorithm for ASAR Wide Swath time series
}

\author{
J. Van doninck ${ }^{1}$, J. Peters ${ }^{2}$, H. Lievens ${ }^{1}$, B. De Baets ${ }^{2}$, and N. E. C. Verhoest ${ }^{1}$ \\ ${ }^{1}$ Laboratory of Hydrology and Water Management, Ghent University, Coupure links 653, Ghent, Belgium \\ ${ }^{2}$ Department of Mathematical Modelling, Statistics and Bioinformatics, Ghent University, Coupure links 653, Ghent, Belgium
}

Correspondence to: J. Van doninck (jasper.vandoninck@ugent.be)

Received: 7 November 2011 - Published in Hydrol. Earth Syst. Sci. Discuss.: 23 November 2011

Revised: 14 February 2012 - Accepted: 4 March 2012 - Published: 8 March 2012

\begin{abstract}
A change detection algorithm is applied on a three year time series of ASAR Wide Swath images in VV polarization over Calabria, Italy, in order to derive information on temporal soil moisture dynamics. The algorithm, adapted from an algorithm originally developed for ERS scatterometer, was validated using a simple hydrological model incorporating meteorological and pedological data. Strong positive correlations between modelled soil moisture and ASAR soil moisture were observed over arable land, while the correlation became much weaker over more vegetated areas. In a second phase, an attempt was made to incorporate seasonality in the different model parameters. It was observed that seasonally changing surface properties mainly affected the multitemporal incidence angle normalization. When applying a seasonal angular normalization, correlation coefficients between modelled soil moisture and retrieved soil moisture increased overall. Attempts to account for seasonality in the other model parameters did not result in an improved performance.
\end{abstract}

\section{Introduction}

Up till now, the operational retrieval of spatially distributed soil moisture from remote sensing systems is limited to coarse resolution radiometers and scatterometers. Different algorithms have been developed to derive soil moisture products from C- and X-band Advanced Microwave Scanning Radiometer - Earth Observing System (AMSR-E) data (Njoku et al., 2003; Koike et al., 2004; Owe et al., 2008) and several global soil moisture products are made available to the scientific community. Additionally, development and validation of soil moisture products from the L-band Soil Moisture and Ocean Salinity (SMOS) mission are currently ongoing (Kerr et al., 2010). Other global soil moisture products were generated from data collected by the scatterometers onboard the European Remote Sensing satellites ERS-1 and ERS-2 and their successor, the advanced scatterometer (ASCAT), onboard the MetOp satellites (Wagner et al., 1999b; Bartalis et al., 2007; Naeimi et al., 2009). All of these sensors are characterized by a low spatial resolution $(25-50 \mathrm{~km})$, which makes them of limited utility for applications at finer scales.

Synthetic Aperture Radar (SAR) systems can reach much higher spatial resolutions, making them attractive for applications on watershed and field scale. Despite the large volume of research conducted on the derivation of soil moisture from SAR, routinely produced soil moisture maps are not yet available. The difficulty of mapping soil moisture from SAR lies in the nature of the reflected signal, which is, apart from soil moisture, also influenced by terrain properties such as topography, vegetation cover and soil roughness. Separating the soil moisture contribution to the backscatter signal from the roughness and vegetation contribution has been attempted using physical backscatter models in combination with multiple-polarized and/or multi-angular data (Zribi et al., 2005, 2007; Baghdadi et al., 2006; Rahman et al., 2008; Gherboudi et al., 2011) or by using effective roughness parameters (Su et al., 1997; Baghdadi et al., 2002; Rahman et al., 2007; Lievens et al., 2011; Lievens and Verhoest, 2011). However, the satellite and/or ancillary data required in these models are seldom readily available.

Alternatively, the modelling or description of vegetation and soil roughness has been circumvented using a multitemporal approach. When comparing two or more images over the same site, obtained over a time frame in which only minor vegetation or soil roughness variations occur, changes in backscatter can be attributed to changes in soil moisture (Narayan et al., 2006). Shoshany et al. (2000), for example, suggested to use a normalized difference of SAR backscatter of two images as an indicator of soil moisture changes 
between the times of image acquisition. On a larger time series of 10 SAR images over one month time, Wickel et al. (2001) found high correlations between soil moisture change and backscatter change for wheat stubble fields. Pathe et al. (2009) presented a methodology, based on the ERS scatterometer and ASCAT soil moisture retrieval algorithm developed at the TU Wien (Wagner et al., 1999b), to derive a $1 \mathrm{~km}$ soil moisture index from ENVISAT ASAR in Global Monitoring (GM) mode and applied it to 697 ASAR GM images over Oklahoma. The same product was validated using in situ and airborne soil moisture data over an area in southeastern Australia (Mladenova et al., 2010).

These kinds of multitemporal approaches offer opportunities for routinely mapping soil moisture at high spatial resolution with the upcoming Sentinel-1 mission (Attema et al., 2007). This mission, a constellation of two C-band radar satellites of which the first is to be launched in 2013, is expected to cover the European land surface every four days in Interferometric Wide Swath (IWS) mode. In IWS mode, Sentinel-1 will cover a swath of $250 \mathrm{~km}$ at $5 \times 20 \mathrm{~m}$ resolution in either VV $+\mathrm{VH}$ or $\mathrm{HH}+\mathrm{HV}$ polarization. Given the large data volume to be provided by Sentinel-1, soil moisture change detection techniques developed for ASAR are likely to be applicable and improved for Sentinel-1 data. One big challenge in a multitemporal soil moisture retrieval, however, remains the characterization of the influence of seasonally changing vegetation on the backscatter signal (Wagner et al., 2009).

In this study, a change detection method is applied on a $3 \mathrm{yr}$ time series over Calabria, Italy, to infer a soil moisture index from ASAR Wide Swath data. The change detection is preceded by an angular correction to be able to compare images with different viewing geometries and validated using a hydrological model. Additionally, the influence of vegetation phenology in the different processing steps is assessed using a simple vegetation index from optical remote sensing.

\section{Study area and datasets}

\subsection{Study area}

The peninsula of Calabria (Fig. 1) is situated in the southwestern tip of mainland Italy, measuring approximately $250 \mathrm{~km}$ in length and $30 \mathrm{~km}$ to $100 \mathrm{~km}$ in width, and is dissected longitudinally by a mountain range with elevations up to approximately $2000 \mathrm{~m}$. Soil structure varies greatly, with clayey soils at the eastern side of the peninsula and more sandy soils at the western part.

Agriculture is concentrated in the lower elevation ranges and consists of both arable land and permanent crops. Of the latter, citrus and olive groves occur over large areas. Due to the Mediterranean climate, agriculture at the lower elevations is rainfall limited and (mainly cereal) crops exhibit a winter growing season. At the central plateaus, different growing cycles may occur as a result of lower temperatures and hence energy limited vegetation growth.

\subsection{Satellite data}

A total of 80 descending mode Advanced Synthetic Aperture Radar (ASAR) Wide Swath (WS) images, completely or partially covering Calabria, were acquired between January 2008 and December 2010. The WS mode is one of the ScanSAR modes of ASAR and covers a swath of $405 \mathrm{~km}$ width with a spatial resolution of $150 \mathrm{~m}$ and a radiometric accuracy of approximately $0.6 \mathrm{~dB}$. The temporal resolution is limited due to conflicting data acquisitions in other modes (especially over Europe) and the maximum duty cycle of $30 \%$ in WS mode. This results in the availability of on average 2.2 ASAR WS images per month over Calabria.

In order to obtain information on vegetation dynamics, Moderate Resolution Imaging Spectroradiometer (MODIS) Normalized Difference Vegetation Index (NDVI) images were acquired through the USGS Land Processes Distributed Active Archive Center. Since NDVI changes only slowly over time (Fensholt and Sandholt, 2003), 16-day composite images at $1 \mathrm{~km}$ resolution were considered adequate to describe the yearly vegetation behaviour.

The strong topography in Calabria is expected to cause geometric and radiometric distortions in the ASAR data. In order to account for influences of topography, the Shuttle Radar Topography Mission (SRTM) digital elevation model (DEM), version 4.1 (Jarvis et al., 2008) was used in the ASAR preprocessing. The SRTM DEM is distributed at 3 " (approximately $90 \mathrm{~m}$ ) resolution.

The accuracy of the ASAR WS soil moisture index derived in this study is compared to accuracies of three operational coarse resolution soil moisture products. Two products are derived from AMSR-E passive microwave data, each by applying a different algorithm. AMSR-E soil moisture products derived using the algorithm developed by NASA (Njoku et al., 2003) are distributed by the National Snow and Ice Data Center (Njoku, 2008). For this study, Level 3 descending mode soil moisture for the entire period 2008-2010 was acquired. The second AMSR-E product, based on the Land Parameter Retrieval Model (LPRM, Owe et al., 2008) developed by the Vrije Universiteit Amsterdam (VUA) in collaboration with NASA, is provided through the ADAGUC web portal (http://geoservices.falw. vu.nl/adaguc_portal_dev/). Both AMSR-E products are distributed in $0.25^{\circ}$ pixel grids. Descending orbit soil moisture was selected since these are assumed to provide more accurate estimates (Draper et al., 2009; Jackson et al., 2010), although this was contradicted in a recent comparative study (Brocca et al., 2011). The third coarse resolution product used for comparison is the TU Wien-EUMETSAT ASCAT surface soil moisture product (Bartalis et al., 2007; Naeimi et al., 2009), based on a change detection algorithm. ASCAT data were provided by the TU Wien Institute of 


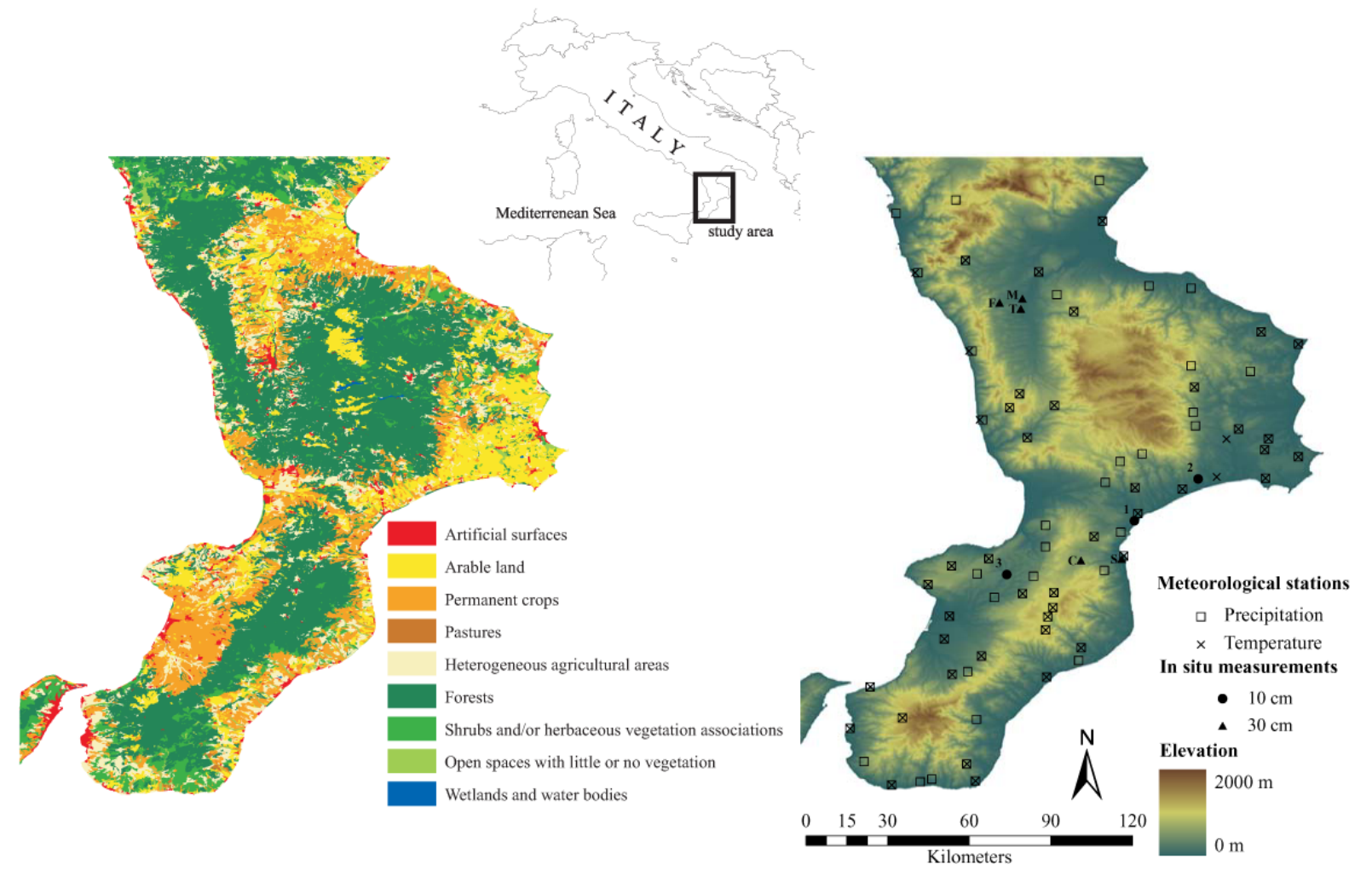

Fig. 1. Left panel: Corine land cover 2000 map of the study site. Right panel: topography of the study site and location of meteorological stations and in situ measurement locations $(\mathrm{F}=$ Fitterizzi, $\mathrm{M}=$ Mongrassano, $\mathrm{T}=$ Torano, $\mathrm{C}=$ Chiaravalle, $\mathrm{S}=\mathrm{Satriano}$ ).

Photogrammetry and Remote Sensing (IPF) in a Discrete Global Grid with grid spacing of approximately $12.5 \mathrm{~km}$.

\subsection{Soil moisture data}

Validation of low to medium resolution remotely sensed soil moisture products using in situ point measurements is difficult because of the scale gap between both and because of the limited availability of in situ measurements over large regions and over large timespans. As a viable alternative, hydrological models are used as a basis for the validation of soil moisture products (Sandholt et al., 2002; Pellarin et al., 2006).

\subsubsection{Hydrological model structure and inputs}

A spatially distributed soil moisture model, inspired by the hydrological BEACH model of Sheikh et al. (2009), was used here to estimate the soil moisture contents of the topsoil. This particular model was selected because the soil moisture model needed to (1) run on a limited amount of readily available input data, (2) explicitly account for soil texture, (3) be spatially distributed, and (4) provide soil moisture estimates on a daily basis. The basic processes incorporated in the model are precipitation, infiltration, transpiration and evaporation. The soil water balance at location $i$ is calculated as:

$D \frac{\Delta \Theta_{i}}{\Delta t}=P_{i}-\mathrm{RO}_{i}-\mathrm{ET}_{i}-S_{i}$,

where $D$ is the depth of soil moisture simulation [mm], $\Theta$ is the soil moisture content $\left[\mathrm{m}^{3} \mathrm{~m}^{-3}\right], P$ is precipitation $\left[\mathrm{mm} \mathrm{day}^{-1}\right], \mathrm{RO}$ is runoff $\left[\mathrm{mm} \mathrm{day}^{-1}\right]$, ET is evapotranspiration $\left[\mathrm{mm} \mathrm{day}^{-1}\right], S$ is percolation to deeper soil layers $\left[\mathrm{mm} \mathrm{day}^{-1}\right]$, and $\Delta t$ is the model time step [day].

Runoff was estimated by a bucket model assuming that infiltration $(I)$ proceeds until the infiltration capacity of the topsoil has been reached (Sheikh et al., 2009):

$\mathrm{RO}_{i}=P_{i}-I_{i}$ if $P_{i}>I_{i}$,

where the infiltration was defined as:

$I_{i}=\min \left[P_{i},\left(\Theta_{\mathrm{sat}_{i}}-\Theta_{i}\right) D\right]$,

where the soil moisture content at saturation $\left(\Theta_{\text {sat }}\right.$, soil water potential $(\psi)$ of $-0.1 \mathrm{kPa}$ ) was estimated through its empirical relationship with soil texture and soil organic matter content (Saxton et al., 1986; Saxton and Rawls, 2006). Daily 
evapotranspiration was estimated as a soil moisture dependent fraction of its potential rate $\left(\mathrm{ET}_{\mathrm{p}}\right.$; Hamon, 1963):

$\mathrm{ET}_{\mathrm{p}}=0.0138 L_{i}\left[\rho_{\mathrm{sat}_{i}}\left(T_{i}\right)\right]$

and

$\mathrm{ET}_{i}=K_{\mathrm{r}} \mathrm{ET}_{\mathrm{p}}$,

with $K_{\mathrm{r}}= \begin{cases}0, & \text { if } \Theta_{i}<\Theta_{\mathrm{dry}_{i}} \\ \Theta_{i}-\Theta_{\mathrm{dry}_{i}}, & \text { if } \Theta_{\mathrm{dry}_{i}}<\Theta_{i}<\Theta_{\mathrm{fc}_{i}}, \\ \Theta_{\mathrm{fc}_{i}}-\Theta_{\mathrm{dry}_{i}} & \text { if } \Theta_{i}>\Theta_{\mathrm{fc}_{i}}\end{cases}$

where $L$ is day length $[\mathrm{h}], \rho_{\text {sat }}(T)\left[\mathrm{g} \mathrm{m}^{-3}\right]$ the saturated absolute humidity at the mean daily air temperature $T$. $\Theta_{\mathrm{fc}}$ and $\Theta_{\text {dry }}$ are the soil moisture content at field capacity (soil water potential of $-33 \mathrm{kPa}$ ) and air dryness (soil water potential of $-22000 \mathrm{kPa}$ ), respectively, and $K_{\mathrm{r}}$ is a dimensionless reduction constant, depending on the actual soil moisture content. If the actual soil moisture content is higher than the soil moisture content at field capacity, then evapotranspiration is at its potential rate. If the soil moisture content is lower, then the actual evapotranspiration is lower than its potential rate. This reflects the two evapotranspirative stages: an energy limiting stage $\left(K_{\mathrm{r}}=1\right)$ and a soil moisture limiting stage $\left(K_{\mathrm{r}}<1\right)$ (Sheikh et al., 2009, and references therein).

The percolation was estimated as (Raes, 2002):

$S_{i}=D \tau_{i}\left(\Theta_{\mathrm{sat}_{i}}-\Theta_{\mathrm{fc}_{i}}\right) \frac{e^{\Theta_{i}-\Theta_{\mathrm{fc}_{i}}}-1}{e^{\Theta_{\mathrm{sat}_{i}}-\Theta_{\mathrm{fc}_{i}}-1}}$, if $\Theta_{i}>\Theta_{\mathrm{fc}_{i}}$,

where $\tau$ is a dimensionless drainage characteristic that is related to the saturated hydraulic conductivity ( $K_{\mathrm{sat}}$ $\left[\mathrm{mm} \mathrm{day}^{-1}\right]$ ) as:

$\tau_{i}=0.0866 e^{0.8063 \log K_{\text {sat }_{i}}}$.

Meteorological data on precipitation and mean air temperature were provided by the Agenzia Regionale per la Protezione dell'Ambiente della Calabria (http://www.arpacal.it) on a daily basis. Precipitation and temperature data from 73 and 45 meteorological stations, respectively, recorded during the period 2008-2010, were used in this study. The spatial coverage of meteorological stations is illustrated in Fig. 1.

The (linear) correlation coefficient $(R)$ between altitude on the one hand and precipitation and temperature on the other hand was low for precipitation $(R=0.08)$ and high for temperature $(R=-0.72)$. Therefore, ordinary kriging and regression kriging were selected as suitable spatial interpolation techniques for precipitation and temperature, respectively. Regression kriging combined a linear regression of the air temperature on auxiliary topography data (SRTM) with kriging of the regression residuals to obtain a daily mean air temperature map for Calabria. The open-source gstat extension package (Pebesma, 2004) for $R$ (Version 2.10.2009-1210, http://www.r-project.org) was used for these geostatistical operations.
A digital soil map developed on more than 7000 soil samples and provided by the Agenzia Regionale per lo Sviluppo e per i Servizi in Agricoltura (ARSSA, 2003) was used as a modelling basis. The map contains information on several soil characteristics, including soil texture (sand [\%], silt [\%], clay [\%]) and soil organic matter content [\%]. Each of the total of 2166 soil map polygons with known soil properties was used as spatial entity $i$. Daily interpolated precipitation and air temperature data were allocated to these polygons, and together with the observed soil texture and organic matter content, the data requirements to solve the soil moisture balance (Eq. 1) were met.

\subsubsection{Hydrological model validation}

Validation of the hydrological model was performed using two independent datasets. The first dataset is collected at five permanent in situ measurement stations (Fig. 1), operated by the Centro Funzionale Multirischi della Calabria (http://www.cfcalabria.it). At these stations, soil moisture measurements are recorded at 30,60 and $90 \mathrm{~cm}$ depth at hourly intervals. These data are provided to the scientific community through the International Soil Moisture Network (Dorigo et al., 2011). For this study, hourly soil moisture measurements at $30 \mathrm{~cm}$ depth for the year 2009 were averaged to daily values and compared to daily modelled moisture of the top $30 \mathrm{~cm}$ soil layer (Fig. 2). The hydrological model overestimates the dynamic range of soil moisture, which is partly due to the fact that the hydrological model provides an average over the $30 \mathrm{~cm}$ top layer, while in situ measurements reflect the soil moisture content at a depth of $30 \mathrm{~cm}$ only. Uncertainty or missing information on model parameters might additionally result in discrepancies between the absolute soil moisture values. Nevertheless, strong correlations between in situ and modelled soil moisture are found for all five stations. When rescaling both measured and modelled soil moisture between the maximum and minimum values of the time series, it can be seen that some of the largest gaps occur when the model predicts a soil moisture increase as a result of a rainfall event while this rainfall event did not occur at the in situ site, or vice versa. This is because the accuracy of interpolation between meteorological stations is limited when precipitation is strongly localized.

A second validation of the model was performed using volumetric soil moisture content measurements over a depth of $10 \mathrm{~cm}$ obtained during a dedicated field campaign from 16 September 2009 until 8 October 2009. Measurements were made at three different locations (Fig. 1) using a portable Time Domain Reflectometry (TDR, Topp and Reynolds, 1998) tool (TRIME-PICO64 probe, IMKO $\mathrm{GmbH}$, Germany). Measurements were taken daily or every two days, and a total of 50 volumetric soil moisture measurements were made. Each measurement represented an average of three repeated observations during the same sampling occasion. Dry conditions preceded the measurement campaign, 

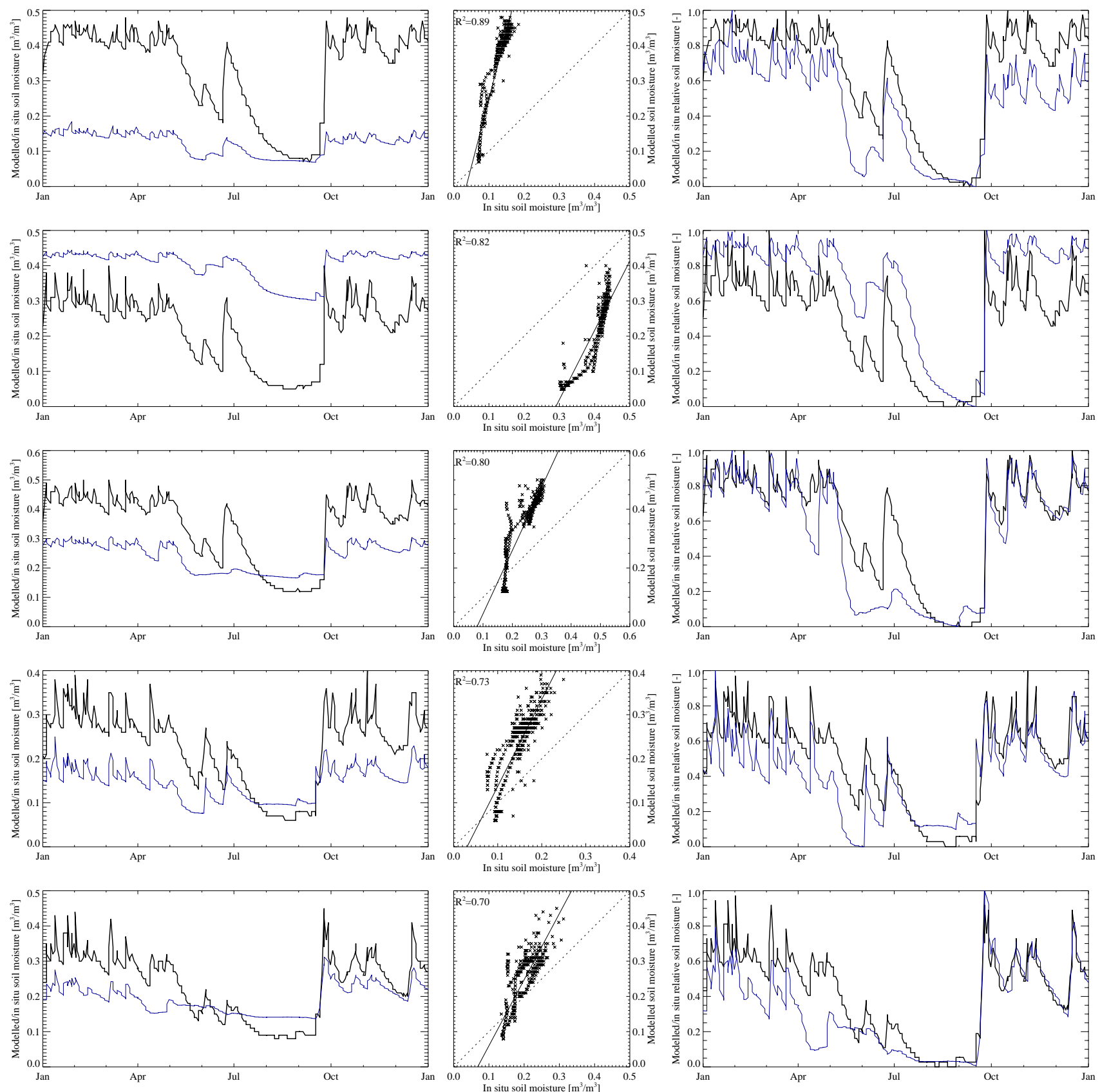

Fig. 2. Validation of modelled soil moisture over $30 \mathrm{~cm}$ depth at (from top to bottom) Fitterizzi, Mongrassano, Torano, Chiaravalle and Satriano in situ stations (see corresponding annotations in Fig. 1). Left column: modelled (thick line) and in situ (blue line) volumetric soil moisture content during the year 2009. Middle column: scatterplot of in situ and modelled soil moisture for the same period. Right column: modelled (thick line) and in situ (blue line) relative soil moisture during the same period.

but during the campaign several precipitation events occurred, resulting in subsequent wetting and drying of the soil, and a range of soil moisture states at the three soil moisture sampling locations. Comparison of simulated $(10 \mathrm{~cm})$ and measured soil moisture (Fig. 3) resulted in a root mean squared error (RMSE) of $0.073 \mathrm{~m}^{3} \mathrm{~m}^{-3}$ and $R^{2}=0.47$.
Notwithstanding the simplicity of the hydrological model, temporal changes in soil moisture content are well captured for both the $10 \mathrm{~cm}$ and $30 \mathrm{~cm}$ top soil layer. Modelled volumetric soil moisture content of the top $10 \mathrm{~cm}$ layer was derived for the entire study area on a daily basis for the period 2008-2010 as reference values for the remotely sensed 


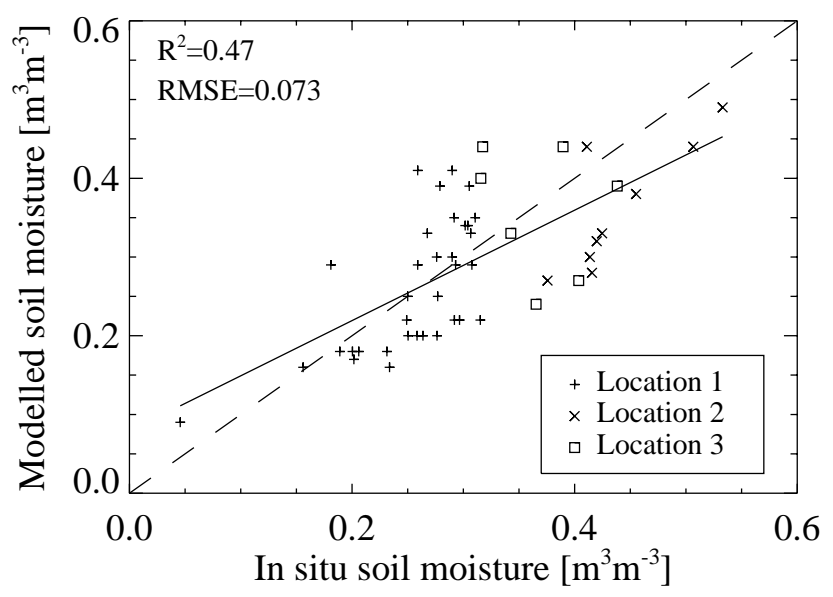

Fig. 3. Validation of modelled soil moisture over $10 \mathrm{~cm}$ depth at three in situ measurement locations (see corresponding annotations in Fig. 1).

soil moisture. Although the microwave penetration depth is limited to approximately $5 \mathrm{~cm}$, a reference depth of $10 \mathrm{~cm}$ is chosen here since modelled soil moisture over thinner layers could not be validated. The soil moisture maps were finally resampled to the $1 \mathrm{~km}$ resolution of MODIS data. Ideally, a soil moisture model with smaller time steps, e.g. hourly, would be used for validation in order to avoid errors introduced by varying meteorological conditions throughout the day. This would however require rainfall and temperature measurements at smaller intervals, which were not available for the study site.

\section{Methods}

\subsection{ASAR preprocessing}

ASAR WS images are provided by ESA at level 1B preprocessing, which includes slant range to ground range corrections and resampling to a $75 \mathrm{~m}$ pixel spacing. Further preprocessing was performed using Next ESA SAR Toolbox (NEST) software and included geometric correction by a Range-Doppler orthorectification (Small and Schubert, 2008), using the SRTM DEM and DORIS precise orbit files, and radiometric calibration.

Effects on backscatter due to varying incidence angle were corrected by a pixel-wise multitemporal incidence angle normalization (Loew et al., 2006; Zribi et al., 2007; Wagner et al., 2008; Pathe et al., 2009). Using a linear model, which is sufficient for the range of incidence angles covered in Wide Swath mode, the incidence angle normalization is expressed as:

$\sigma^{0}(30)=\sigma^{0}(\theta)-\beta\left(\theta-30^{\circ}\right)$,

where $\sigma^{0}(\theta)$ is the backscatter coefficient $[\mathrm{dB}]$ at incidence angle $\theta\left[{ }^{\circ}\right]$ and $\sigma^{0}(30)$ the backscatter coefficient normalized to an incidence angle of $30^{\circ}$. The angular correction coefficient $\beta\left[\mathrm{dB} /{ }^{\circ}\right]$ is found through linear regression between $\theta$ and $\sigma^{0}(\theta)$ for all the observations over an image pixel.

Because of the relative low resolution of the SRTM DEM, ASAR WS images were resampled to $1 \mathrm{~km}$ resolution prior to incidence angle normalization. Downscaling to $1 \mathrm{~km}$ resolution was also done to be able to compare the ASAR data with the coarser resolution MODIS NDVI data and the soil moisture data obtained from the hydrological model, even though this implies a reduction of spatial resolution to that of ASAR in Global Monitoring mode. Additionally, pixels with slopes higher than $20^{\circ}$ were masked and discarded for further analysis since the linear model is not necessarily valid for the range of incidence angles that is obtained at these slopes.

\subsection{Soil moisture estimation}

The change detection model initially developed for ERS scatterometer and MetOp ASCAT (Wagner et al., 1999b; Naeimi et al., 2009), and subsequently applied on ASAR Global Monitoring (Pathe et al., 2009; Mladenova et al., 2010) and Wide Swath (Wagner et al., 2008) data, was adopted in this study. In this multitemporal model, a relative surface soil moisture index is expressed as:

$\Theta_{\mathrm{ASAR}}=\frac{\sigma^{0}(30)-\sigma_{\mathrm{dry}}^{0}(30)}{S}$,

where $\sigma_{\text {dry }}^{0}(30)$ is the dry reference backscatter $[\mathrm{dB}]$, the pixel's backscatter coefficient at entirely dry conditions, and $S$ is the sensitivity of the backscatter coefficient to soil moisture variations $[\mathrm{dB}]$. The sensitivity is defined as the difference between $\sigma_{\text {dry }}^{0}(30)$ and $\sigma_{\text {wet }}^{0}(30)$, the wet reference backscatter $[\mathrm{dB}]$, the pixel's backscatter at entirely wet conditions:

$S=\sigma_{\text {wet }}^{0}(30)-\sigma_{\text {dry }}^{0}(30)$.

Dry and wet reference backscatter are extracted from $\sigma^{0}(30)$ time series per pixel, where $\sigma_{\text {dry }}^{0}(30)$ is defined as the average of the $5 \%$ lowest backscatter coefficients in the time series and $\sigma_{\text {wet }}^{0}(30)$ is the average of the $5 \%$ highest backscatter coefficients. The $5 \%$ averages are used to reduce possible noise effects. Although the dry reference and sensitivity can be expected to change seasonally as a result of vegetation phenology, $\sigma_{\text {dry }}^{0}(30)$ and $S$ are here initially treated as constants. Effects of neglecting the seasonal variations of vegetation are discussed later. Since $\Theta_{\mathrm{ASAR}}$ is a value between zero (under entirely dry conditions) and one (under fully saturated conditions), the modelled soil moisture is also rescaled to this range using the extreme values in the time series for each pixel. This way, both $\Theta_{\text {ASAR }}$ and the rescaled modelled soil moisture $\left(\Theta_{\text {model }}\right)$ can be considered to represent the soil's degree of saturation and can be mutually compared. This also helps to reduce the effects of biases in the hydrological model (Fig. 2). 

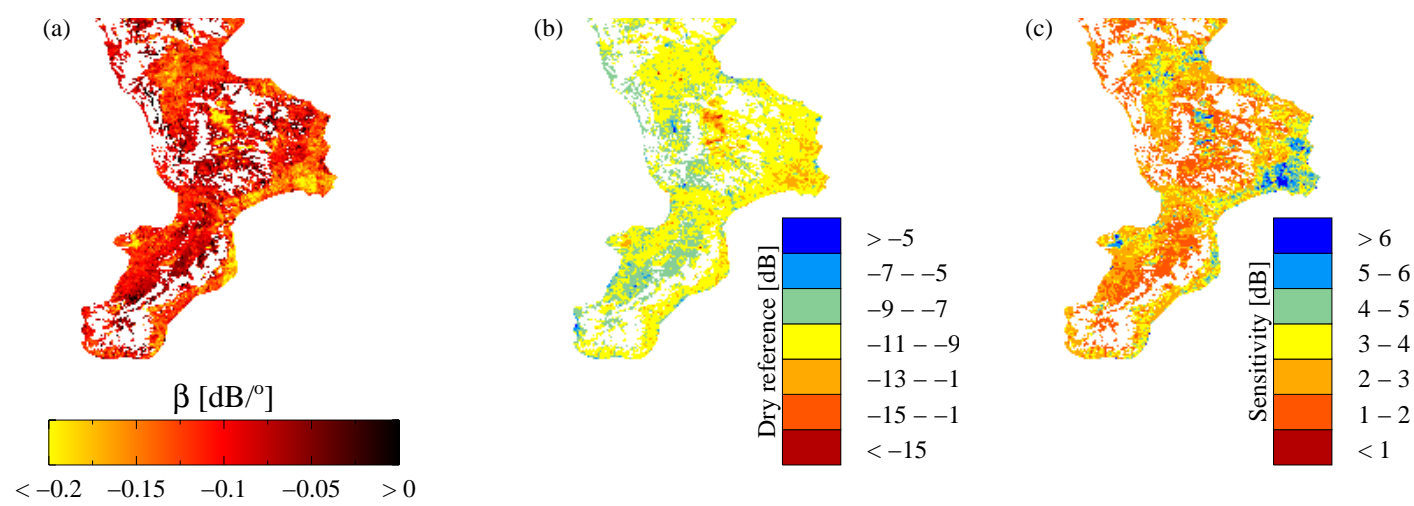

Fig. 4. Angular correction coefficient $\beta$ for each pixel in the study site (a); dry reference backscatter (b); sensitivity of the backscatter to soil moisture changes, derived as the difference between dry reference and wet reference backscatter (c).

\section{Model parameters}

The model parameters (angular correction coefficient $\beta$, dry reference backscatter $\sigma_{\text {dry }}^{0}(30)$ and sensitivity $S$ ) for the study site are displayed in Fig. 4. All three parameters reflect the general land cover pattern, with low $\sigma_{\text {dry }}^{0}(30)$ and $\beta$ and high $S$ over arable land, and an inverse pattern for forested and urban areas. This has been observed in previous studies over different areas (Wagner et al., 1999a, 2008; Pathe et al., 2009).

Dry reference ranges from approximately $-14 \mathrm{~dB}$ over arable land to $-8 \mathrm{~dB}$ for forests, while the sensitivity varies between $1 \mathrm{~dB}$ and $6 \mathrm{~dB}$ for forests and arable land, respectively. Sensitivity values are notably smaller than those found by Wagner et al. (2008) for 73 ASAR WS images over the REMEDHUS soil moisture network in the Duero basin, Spain, where sensitivity ranged from $3 \mathrm{~dB}$ for forests and settlements to $12 \mathrm{~dB}$ over agricultural areas. In the latter study, dry and wet reference, and thus sensitivity, were obtained using the mean backscatter and standard deviation over a time series, assuming a normal distribution of backscatter values. This can explain the difference in the retrieved model parameters. Also, the number of images used in the present study might not be sufficient to correctly identify extreme dry and wet conditions, which will result in an underestimation of $S$. This is enhanced by the selection of dry and wet reference based on the $5 \%$ lowest and highest backscatter coefficients. Longer and denser time series can be expected to result in more stable dry reference and sensitivity estimates.

High sensitivity values, relative to the sensor's radiometric accuracy, are a prerequisite to obtain reliable soil moisture estimates (Mladenova et al., 2010). The low sensitivity values found over much of the study site thus might introduce high retrieval errors. However, ASAR WS backscatter observations at $75 \mathrm{~m}$ pixel spacing have been averaged to a $1 \mathrm{~km}$ grid in the preprocessing step. The noise reduction accompanying this averaging allows these low sensitivity pixels to be further processed.

\section{Vegetation and soil moisture dynamics}

Figures 5a and 6a show the temporal behaviour of $\Theta_{\text {model }}$, $\Theta_{\text {ASAR }}$ and NDVI for two $1 \mathrm{~km}$ pixels, one over arable land (cereal) at low elevation in the eastern part of the study site, the other over high elevation deciduous forests in the central southern part. The arable land pixel clearly exhibits a winter growing season, limited by the availability of soil moisture. The NDVI misses short-term changes in soil moisture and the seasonal cycle lags behind on the soil moisture cycle, which is typical for the conservative response of NDVI to soil moisture changes (Fensholt and Sandholt, 2003). The correlation of 16-day NDVI and $\Theta_{\text {model }}$, averaged over the 16-day compositing period (Fig. 5b), is therefore limited ( $R=0.55)$. ASAR soil moisture shows a similar seasonal pattern for the arable land pixel, although the correlation with modelled soil moisture (Fig. 5c) is much stronger $(R=0.80)$.

For the forest pixel, the NDVI cycle is in antiphase with the soil moisture cycle (Fig. 6a). This is because at this elevation, vegetation growth is energy limited rather than moisture limited, resulting in a summer growing season and a strong negative $(R=-0.60)$ correlation between NDVI and soil moisture (Fig. 6b). ASAR soil moisture for this pixel remains in phase with the modelled soil moisture, although the correlation (Fig. 6c) is much weaker $(R=0.50)$ than for the arable land.

Figure 7 shows the correlation coefficient between $\Theta_{\text {model }}$ and NDVI (Fig. 7a) and $\Theta_{\text {model }}$ and $\Theta_{\text {ASAR }}$ (Fig. 7b) for all pixels in the study site, and confirms what was observed in Figs. 5 and 6. NDVI shows a moderate to strong positive correlation with soil moisture for the lower elevations, both over arable land and over permanent crops (citrus and olive plantations), and a strong negative correlation over forest pixels at high elevations. For arable land at the higher elevations, the correlation coefficient for NDVI is close to zero. Correlation coefficients for ASAR soil moisture are in general much higher, with $R$ values over 0.6 for most of the arable land areas. In regions with permanent crops, $R$ values 


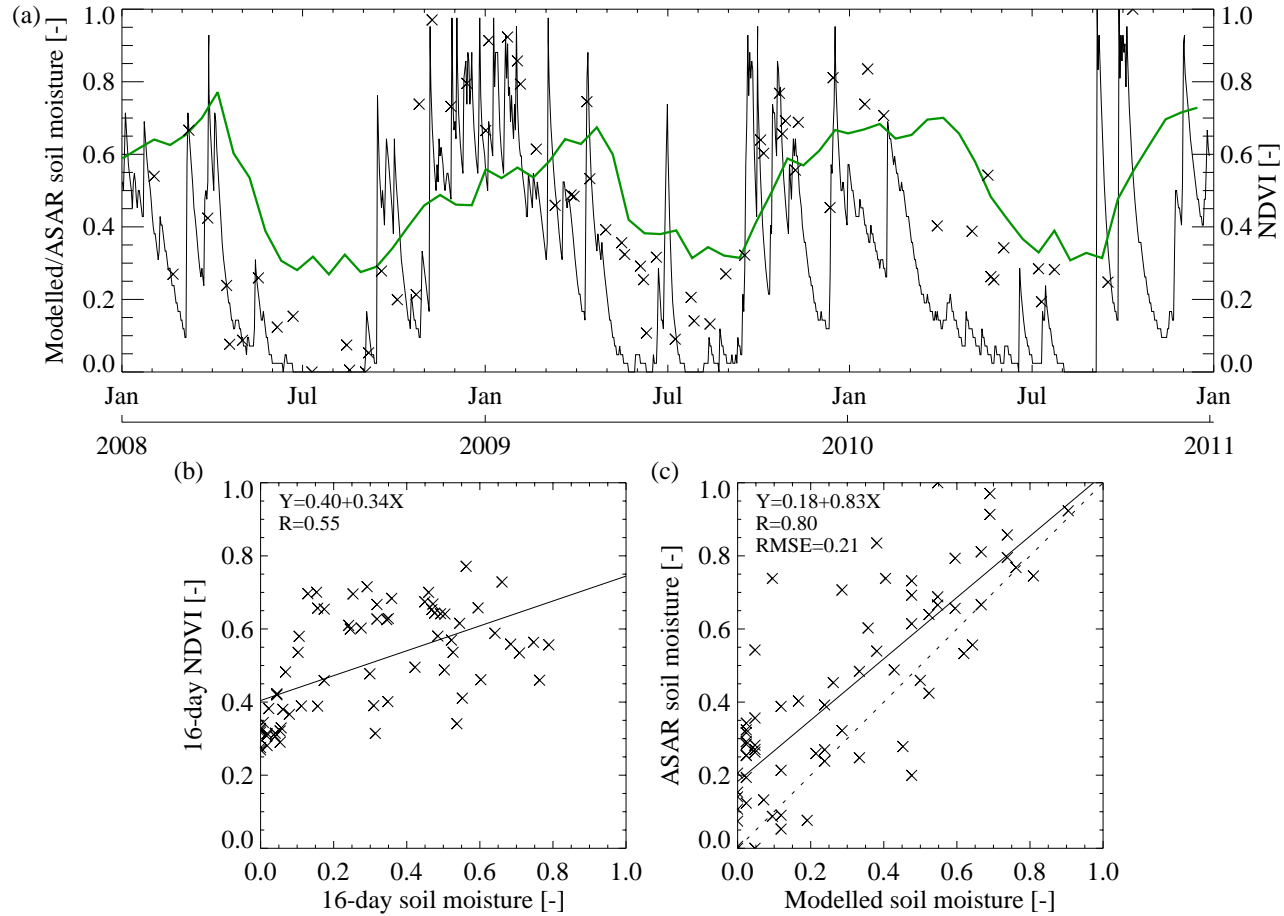

Fig. 5. Temporal behaviour of modelled soil moisture (black line), NDVI (thick green line) and ASAR soil moisture (crosses) for a pixel over arable land (a); scatterplot of modelled soil moisture, averaged over 16 days, and 16-day NDVI for the same pixel (b); scatterplot of modelled soil moisture and ASAR soil moisture for the same pixel (c).
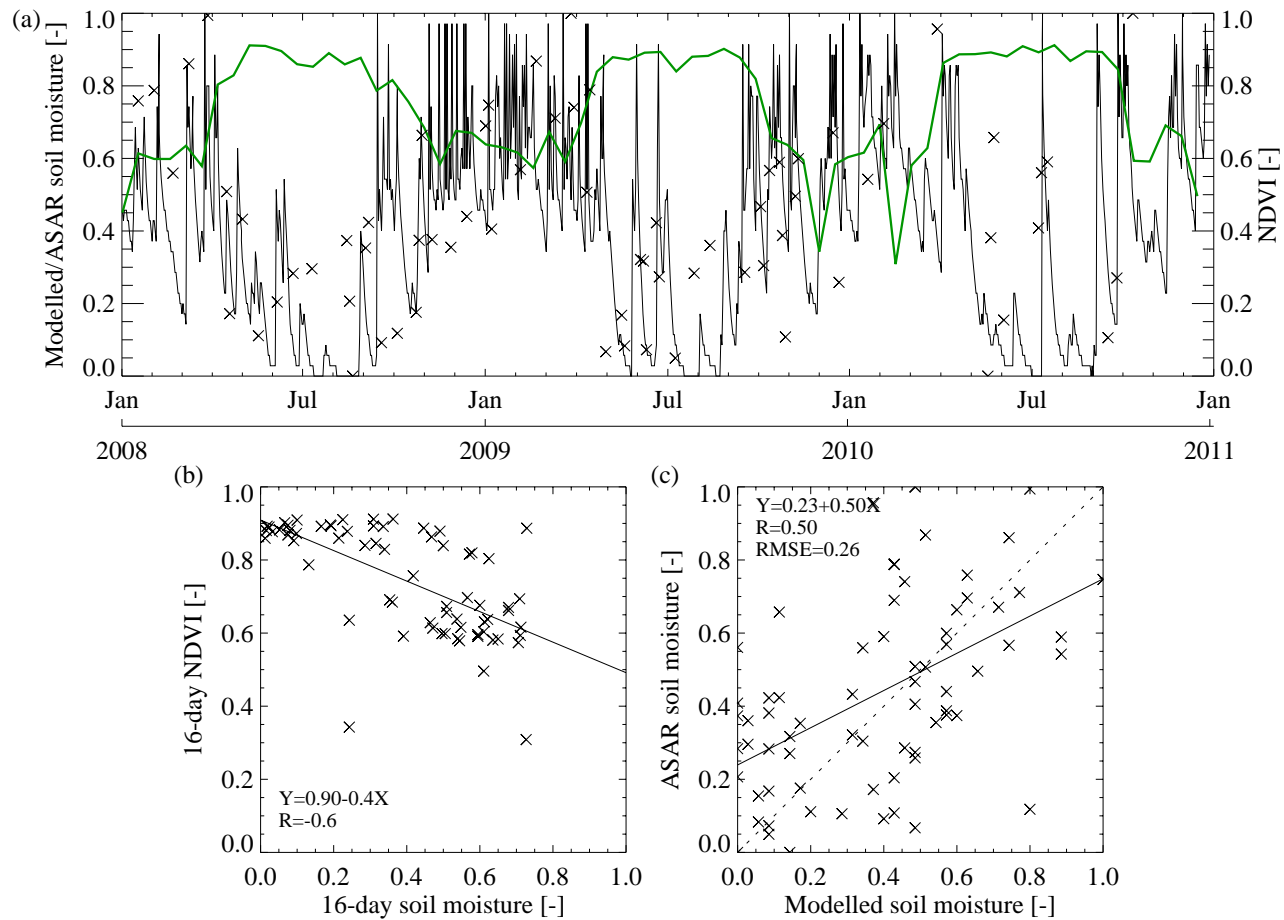

Fig. 6. Temporal behaviour of modelled soil moisture (black line), NDVI (thick green line) and ASAR soil moisture (crosses) for a pixel over deciduous forest (a); scatterplot of modelled soil moisture averaged over 16 days and 16-day NDVI for the same pixel (b); scatterplot of modelled soil moisture and ASAR soil moisture for the same pixel (c). 
(a)
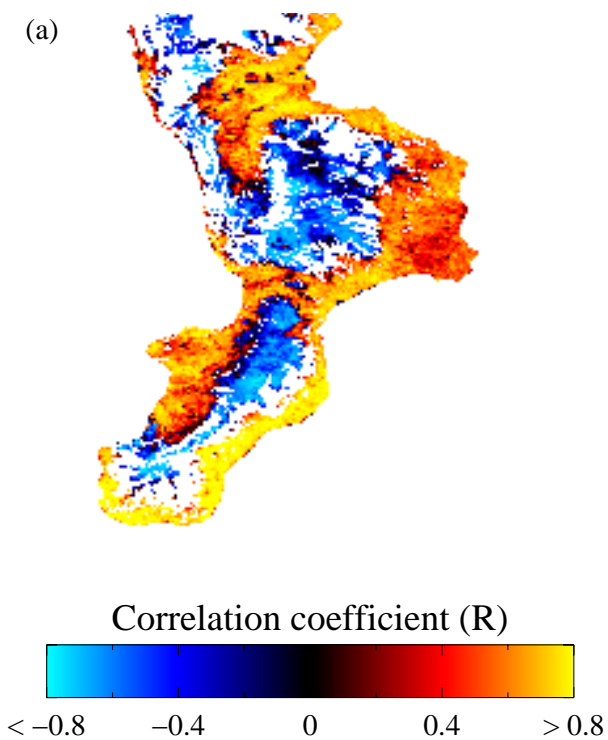

(b)
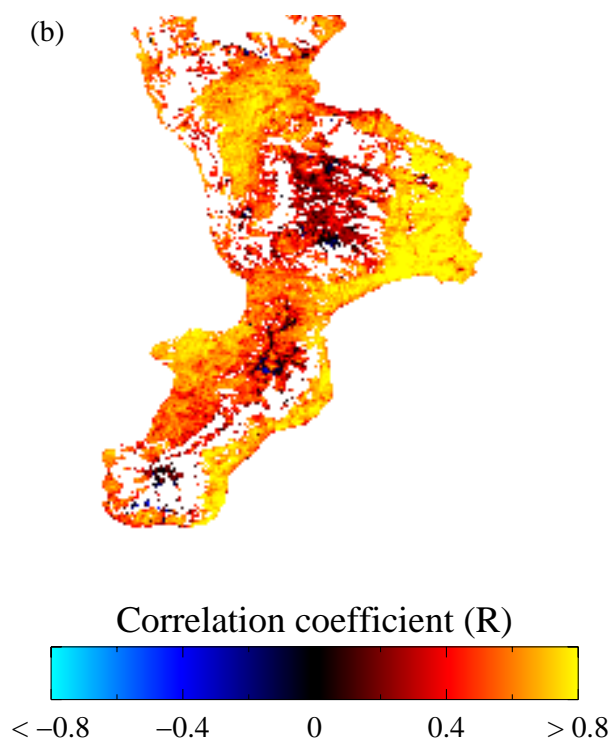

Fig. 7. Correlation coefficients between modelled soil moisture averaged over 16 days and 16-day NDVI (a) and modelled soil moisture and ASAR soil moisture (b), for each pixel of the study site for the 3-yr time series.

for $\Theta_{\text {ASAR }}$ are lower and even slightly lower than those for NDVI. Over forests, $\Theta_{\text {ASAR }}$ is weak to moderate positively correlated with $\Theta_{\text {model }}$.

Regions where NDVI is positively correlated with modelled soil moisture correspond to regions with a strong correlation between ASAR soil moisture and modelled soil moisture. This might suggest that the change detection algorithm, as applied on the ASAR Wide Swath data, does not as such reflect changes in surface soil moisture, but rather changes in vegetation phenology. However, $\Theta_{\text {ASAR }}$ is in general correlated much stronger with $\Theta_{\text {model }}$ than NDVI is, and even in many places where NDVI is negatively correlated with soil moisture, the ASAR change detection method still results in moderate positive correlations. It can thus be assumed that soil moisture dynamics have a much stronger influence on SAR backscatter than vegetation dynamics, and the backscatter signal is influenced by soil moisture even under relatively dense canopies.

Figure $7 \mathrm{~b}$ shows a strong correspondence with the spatial pattern of sensitivity to soil moisture (Fig. 4c), resulting in a correlation coefficient between both images of 0.55 . This confirms the presumption that high $S$ is required to obtain reliable soil moisture estimates. However, correlations of 0.5 and higher are observed for many pixels with sensitivities below $3 \mathrm{~dB}$.

\section{Seasonality effects on the change detection algorithm}

In the preceding, changes in vegetation and surface roughness throughout the year have been ignored in defining the model parameters $\beta, \sigma_{\text {dry }}^{0}(30)$ and $S$, and in the derivation of the ASAR soil moisture index. Nevertheless, all three model parameters are possibly influenced by seasonality effects.

\subsection{Seasonality effects on $\beta$}

Influences of vegetation cover on the multitemporal incidence angle correction coefficient $\beta$ can be observed in Fig. $4 \mathrm{a}$, where vegetated areas in general have a higher (less negative) $\beta$. This is caused by the lower angular dependence of the radar backscatter for vegetation compared to bare soils. The angular dependence can thus be expected to vary seasonally over vegetated surfaces. In the ERS and ASCAT retrieval algorithm, this seasonality was incorporated using the multi-angular capabilities of these sensors (Wagner et al., 1999b). For SAR systems, Loew et al. (2006) derived the parameter $\beta$ for the winter and summer season separately, and found higher values for the summer over a variety of landcover classes in a study area in Germany. This was consistent with the higher vegetation cover during the summer growing season.

Here, seasonality effects on $\beta$ are assessed by performing the linear regression (Eq. 8) for the summer months (41 images between April and September) and the winter months (39 images between October and March) separately, corresponding to the months of minimum, respectively maximum, average rainfall, and roughly corresponding to the yearly vegetation patterns observed in Figs. 5a and 6a. This partitioning is somehow arbitrary since the seasonal vegetation cycle varies over the study site, depending on terrain altitude and land cover. Ideally, the partitioning should use smaller time intervals to fully capture vegetation phenology and/or include information on vegetation dynamics to define the 

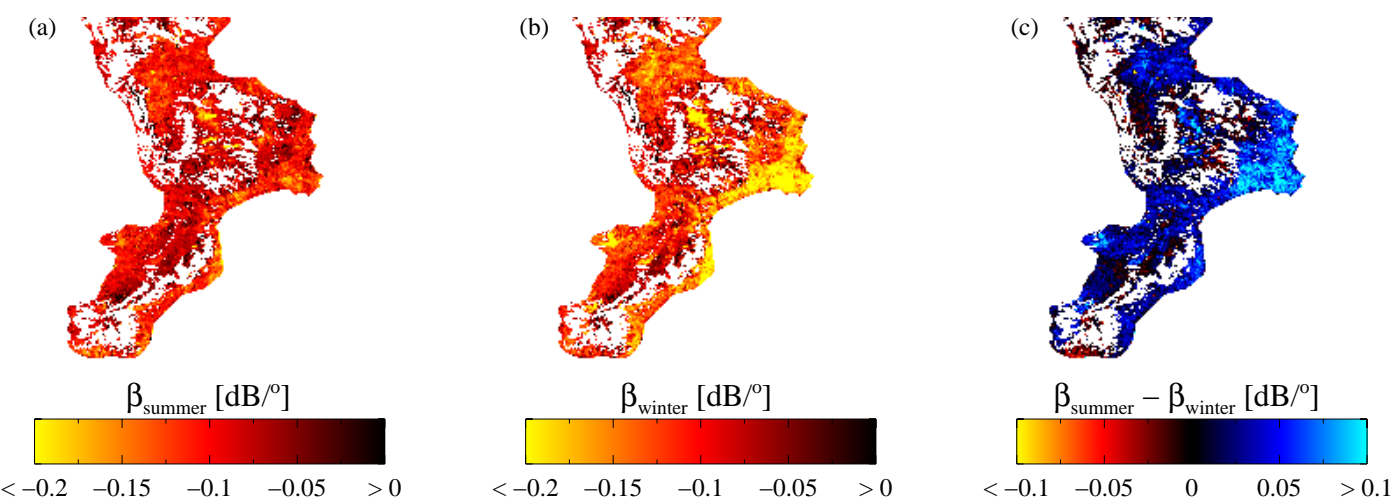

Fig. 8. Angular correction coefficient for the summer months $\beta_{\text {summe }}$ (a), winter months $\beta_{\text {winter }}$

(b) and the difference between $\beta_{\text {summer }}$ and $\beta_{\text {winter }}$ (c).

endpoints of these intervals. This is, however, not feasible in this study due to the limited size of the image dataset.

The correction coefficient for each pixel in the study site for the summer ( $\left.\beta_{\text {summer }}\right)$ and winter $\left(\beta_{\text {winter }}\right)$ months, and the difference between both, is given in Fig. 8. As expected, the largest differences are observed over arable land pixels. Contradictory, however, $\beta$ is lower (more negative) over arable land in winter than in summer, while less negative values would be expected due to overall higher vegetation cover during the winter growing season.

When considering the incidence angle and backscatter coefficient scatterplot (Fig. 9) of the arable land pixel discussed earlier in Fig. 5, it is observed that, for a given incidence angle, backscatter coefficients are, as expected, generally higher during the wet winter than during the dry summer period. The range in $\sigma^{0}(\theta)$ is small (approximately $3 \mathrm{~dB}$ ) at high $\theta$, with small differences between summer and winter backscatter coefficients, and increases to approximately $5 \mathrm{~dB}$ at low incidence angles, causing the regression line of the winter images to be much steeper than the one of summer. A possible explanation for this apparent contradiction is that NDVI is not necessarily a good indicator of wet vegetation biomass, which is the physical property influencing radar backscatter. The time gap between the maxima of NDVI and the slope of the regression line has been observed earlier for ERS scatterometer (Wagner et al., 1999a) and was attributed to a later yearly peak of wet biomass in comparison to NDVI. An alternative explanation is that, apart from vegetation phenology, the seasonal variability of soil moisture also has an influence on $\beta$, although this contradicts previous findings and the basic assumptions of the change detection model (Wagner et al., 1999b). Further research on the angular dependence of backscatter on soil moisture and vegetation cover and their interaction is required to clarify this.

Differences between $\beta_{\text {summer }}$ and $\beta_{\text {winter }}$ are up to $50 \%$ of the correction coefficient derived using all data combined for several pixels in the study site. Incidence angle normalization was therefore performed for the two periods separately,

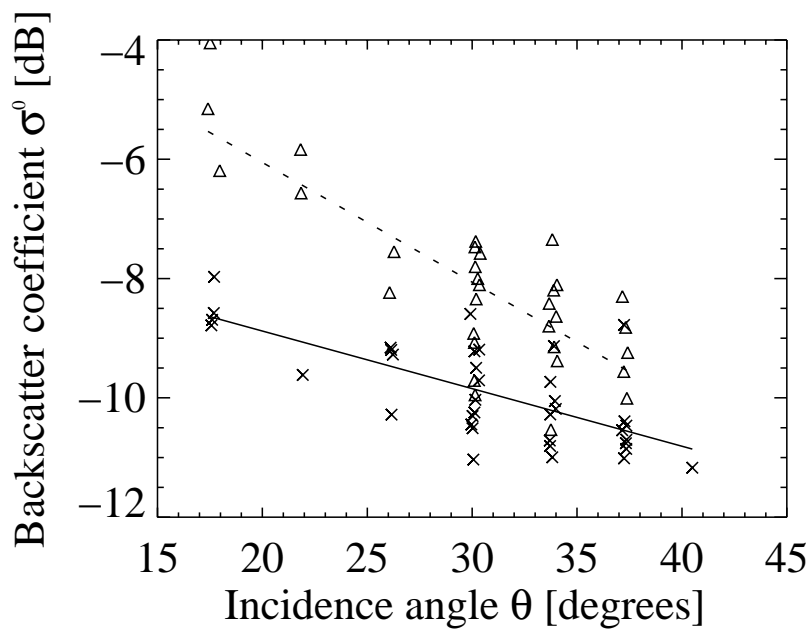

Fig. 9. Angular behaviour of ASAR backscatter for an arable land pixel. Crosses depict observations during summer months, triangles observations during winter months. Linear regression lines for summer and winter are in solid and dashed, respectively.

after which $\sigma_{\text {dry }}^{0}(30)$ and $S$ and the soil moisture index were redefined. The temporal correlation with modelled soil moisture was then determined again for each pixel in the study site. The increase in $R$, relative to the method using a single incidence angle normalization, is given in Fig. 10. Although the average correlation coefficient increases only slightly (Fig. 11), local $R$ increases up to 0.2 are observed at some places in the study site.

Pixels with a strong increase in correlation coefficient do not necessarily correspond to pixels with large differences between $\beta_{\text {summer }}$ and winter $\beta_{\text {winter. }}$. This results from the propagation of uncertainties, as presented by Pathe et al. (2009) and Mladenova et al. (2010), which is proportional to the ratio of the uncertainty on $\beta$ to $S$. Consequently, small changes in $\beta$ can result in significant soil moisture accuracy changes when $S$ is low. For higher sensitivity values, 

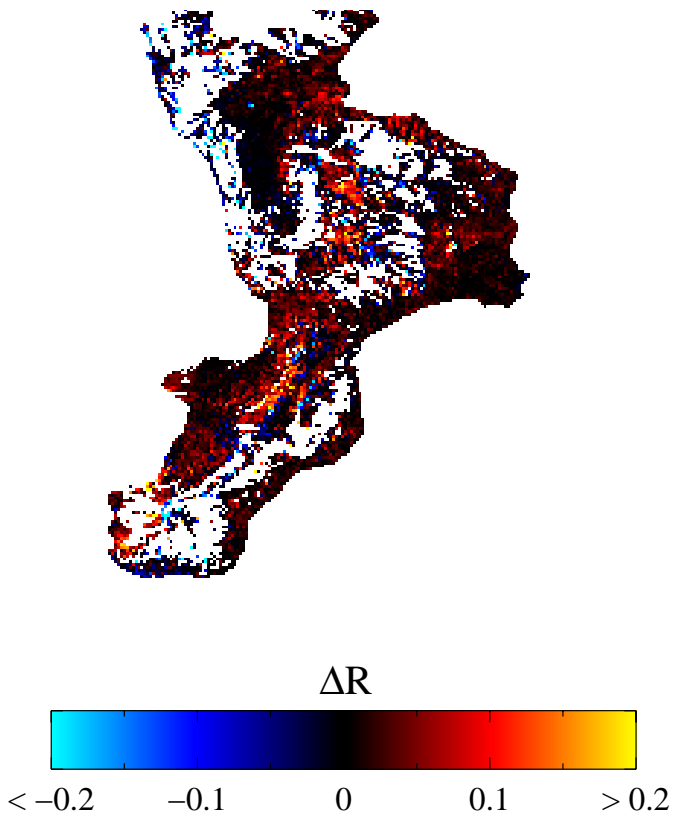

Fig. 10. Increase in correlation coefficient $(\Delta R)$ for the change detection using a seasonal derivation of $\beta$ relative to the method using a fixed $\beta$ for the entire year.

even large changes do not manifestly influence model performance. A good description of the seasonal angular behaviour of SAR backscatter should therefore be incorporated in (future) multitemporal SAR soil moisture algorithms. Estimates of this behaviour at a monthly frequency can be derived when larger image databases become available.

\subsection{Seasonality effects on $\sigma_{\mathrm{dry}}^{0}(30)$ and $S$}

In addition to influences on the angular behaviour of SAR backscatter, seasonality can also be expected to influence the dry reference and sensitivity parameters. For a soil with a constant moisture content, backscatter will change in function of vegetation cover and soil roughness parameters. Both vegetation and roughness can be expected to change seasonally, the former through vegetation phenology and crop growth or harvest, the latter through agricultural practices such as ploughing. Both are likely to perturb the multitemporal soil moisture retrieval, especially over agricultural areas. An example of this can be seen in Fig. 5, where the ASAR soil moisture stays high towards the end of the growing season, where the decrease in vegetation cover lags behind on the decrease in modelled soil moisture. Also, as a result of NDVI being in phase with arable land over most low elevation arable land pixels, sensitivity values for these pixels might be expected to be overestimated. Conversely, $S$ might be underestimated when the vegetation cycle is in antiphase with the soil moisture cycle, e.g. over the high elevation forest pixels.

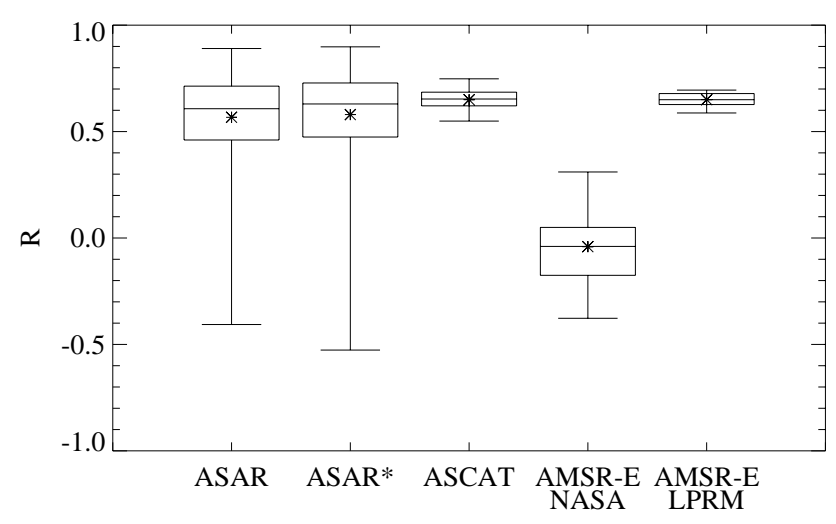

Fig. 11. Box plots of correlation coefficients between modelled soil moisture and ASAR soil moisture using a single angular correction (ASAR), ASAR soil moisture using a seasonal angular correction (ASAR*), TU Wien-EUMETSAT ASCAT surface soil moisture (ASCAT), AMSR-E soil moisture derived using the algorithm developed by Njoku et al. (2003) (AMSR-E NASA) and AMSR-E soil moisture derived using the Land Surface Parameter Model of Owe et al. (2008) (AMSR-E LPRM), for all pixels of the respective products over the study site. Crosses indicate the arithmetic means.

While roughness changes are nearly impossible to assess without multi-angular and/or multi-polarized data or in situ measurements, vegetation dynamics can be easily incorporated using remotely sensed data. In the following, an approach is suggested to incorporate NDVI in the ASAR change detection algorithm. Vegetation phenology is here accounted for using a vegetation index rather than a seasonal description of dry reference and sensitivity, as by Wagner et al. (1999a), because the latter assumes a constant crop behaviour over different years. This might not always be valid, e.g. in the case of crop rotation or when the onset of the growing season varies with the time of rainfall.

In the scatterplot of $\sigma^{0}(30)$ and the corresponding NDVI (Fig. 12) of the arable land pixel, a general positive relationship is observed which is consistent with both NDVI and ASAR backscatter being in phase with the seasonal soil moisture cycle. When considering the modelled soil moisture it is observed that, for low soil moisture levels, radar backscatter increases with increasing vegetation cover. A lower envelope line describing the backscatter behaviour in function of NDVI, by analogy with the concept applied by Moran et al. (2000), can thus be fitted to the data. Instead of scaling $\sigma^{0}(30)$ using a fixed $\sigma_{\text {dry }}^{0}(30)$ and $S$, these can now be replaced by a dry reference and sensitivity changing in function of NDVI.

When comparing the thus derived soil moisture index for this pixel with the index ignoring seasonality, only minor changes in performance are observed. In terms of correlation coefficient between $\Theta_{\text {model }}$ and $\Theta_{\text {ASAR }}$, there is a deterioration from 0.80 to 0.78 , while the RMSE improves slightly from $21 \%$ to $19 \%$. This marginal change in accuracy might 


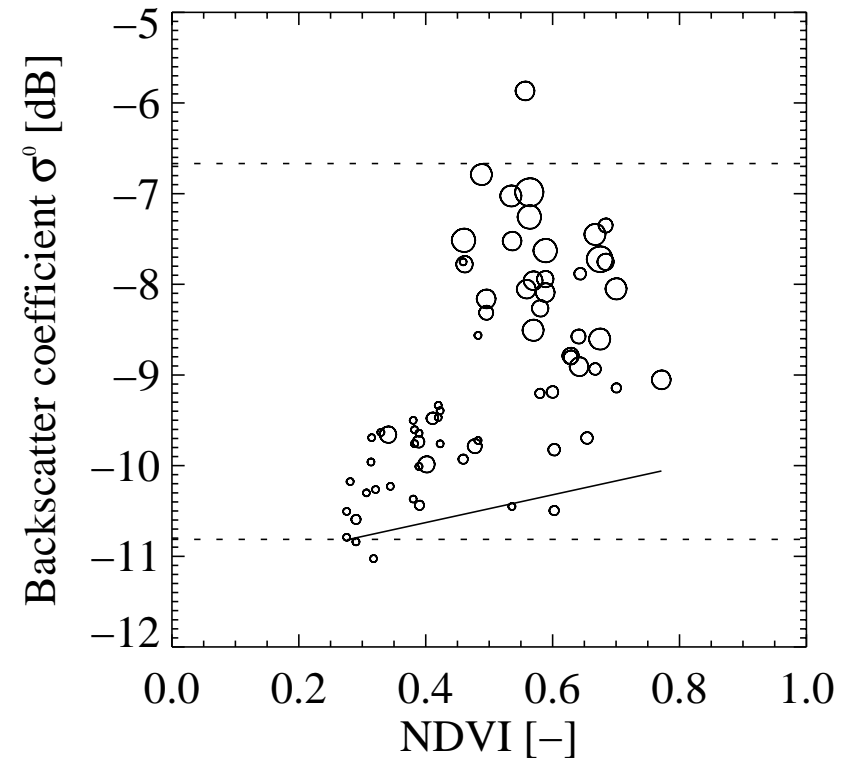

Fig. 12. Scatterplot of NDVI and ASAR WS backscatter for a pixel time series over arable land; the size of the dots represents $\Theta_{\text {model }}$ (large dots indicate high moisture levels). Dotted lines represent the average values of the $5 \%$ highest, respectively lowest, backscatter coefficients, the full line indicates the vegetation dependence of ASAR WS backscatter at low moisture levels.

be due to a number of reasons. First, the hydrolological model's accuracy is likely too low to evaluate small changes in the soil moisture index. Secondly, changes introduced by vegetation phenology might be too small compared to the total sensitivity to soil moisture to improve results, or NDVI might be a bad indicator for effects of vegetation change on backscatter. Finally, effects of soil roughness changes, which are not accounted for in this methodology, might be more important over arable land than changes in vegetation cover. Additionally, incorporating vegetation indices in the derivation of $\sigma_{\text {dry }}^{0}(30)$ and $S$, as suggested here, is only possible when entirely dry conditions are present over the full range of vegetation phenology stages. This is only valid for few pixels in the study site, since this requires long time series at high temporal resolution in order to capture these extreme and possibly rare events.

\section{Comparison to coarse resolution soil moisture products}

The accuracy of the ASAR WS soil moisture was compared to accuracies obtained for coarse resolution soil moisture products (Fig. 11). Validation was performed using the $1 \mathrm{~km}$ hydrological model for the 2008-2010 period, reduced to the spatial resolution of the coarse resolution products. The AMSR-E NASA product was not correlated with modelled soil moisture for this region, while AMSR-E LPRM soil moisture and the TU Wien-EUMETSAT ASCAT surface soil moisture product both produced equally strong correlations. It should however be noted that the VUA-NASA AMSR-E product provides soil moisture estimates for only 10 pixels, all lying in the northern, wider part of the Calabrian peninsula, whereas the ASCAT surface soil moisture provides estimates at 202 grid points distributed over the entire study area. These results are in agreement with the findings of Brocca et al. (2011), who found superior results for AMSR-E LPRM and ASCAT in comparison to AMSR-E NASA over two in situ stations in Calabria. The change detection algorithm applied on ASAR WS data results in $R$ values in the same range as those of the latter two coarse resolution products for most pixels in the study site.

\section{Conclusions}

In this paper, a change detection technique was applied to infer a soil moisture index from a time series of 80 ASAR Wide Swath images over Calabria, Italy. Backscatter coefficients, normalized to an incidence angle of $30^{\circ}$, were scaled between the highest and lowest values in a time series of 3 yr. Strong linear correlations with modelled soil moisture ( $R=0.6$ to $R=0.8$ ) were found for most arable land pixels, while correlation coefficients for forests were moderate to low $(R=0.2$ to $R=0.5)$.

Additionally, an effort was undertaken to account for seasonality effects in the derivation of the three change detection model parameters: angular correction coefficient, dry reference and sensitivity. In the multitemporal incidence angle correction, seasonality was incorporated by deriving the angular correction coefficient for the summer months and winter months separately. Especially for arable land, this resulted in large differences between the summer and winter correction coefficients. When applying the seasonal coefficients in the angular correction, validation with the modelled soil moisture yielded increases in correlation coefficients between 10 and $20 \%$ for many pixels in the study site, thus stressing the importance of an appropriate angular correction. In the derivation of dry reference and sensitivity, seasonality was integrated using MODIS Normalized Difference Vegetation Index. No significant increase in soil moisture estimation accuracy was found, however. This is possibly because errors introduced by vegetation phenology in the derivation of dry reference and sensitivity are small relative to errors from other sources, such as soil roughness or sensor noise.

Overall, change detection algorithms of high to medium spatial resolution and high temporal resolution SAR data, such as ENVISAT ASAR or the upcoming Sentinel-1 mission, offer promising approaches to routinely map surface soil moisture dynamics over a wide range of land cover types. These can be usable additions to low resolution soil moisture datasets from active and passive microwave sensors. Nevertheless, change detection algorithms should not neglect 
influences of seasonality in the derivation of the model parameters, especially the multitemporal angular correction coefficient.

Acknowledgements. This research was funded by the Belgian Federal Science Policy under the Research Programme for Earth Observation Stereo II as part of the EPIDEMOIST project (contract nr. SR/02/124). This research was partly performed in the framework of project G.0837.10 granted by the Research Foundation Flanders. The authors wish to thank the Agenzia Regionale per lo Sviluppo e per i Servizi in Agricoltura (ARSSA) Calabria, Eva De Keyser and Davy Loete for support during the field survey. ASAR WS images were provided by the European Space Agency under the Category-1 Proposal 6944. ASCAT soil moisture data was kindly provided by the TU Wien Microwave Remote Sensing Group. We would like to thank the four reviewer for their valuable comments.

Edited by: A. Loew

\section{References}

ARSSA: I Suoli della Calabria: Carta dei Suoli in Scala 1:250.000, Agenzia Regionale per lo Sviluppo e per i Servizi in Agricoltura, Servizio Agropedologia, 2003.

Attema, E., Bargellini, P., Edwards, P., Levrini, G., Lokas, S., Moeller, L., Rosich-Tell, B., Secchi, P., Torres, R., Davidson, M., and Snoeij, P.: Sentinel-1: The radar mission for GMES operational land and sea services, ESA Bull.-Eur. Space, 131, 10-17, 2007.

Baghdadi, N., King, C., Chanzy, A., and Wigneron, J.: An empirical calibration of the integral equation model based on SAR data, soil moisture and surface roughness measurement over bare soils, Int. J. Remote Sens., 23, 4325-4340, doi:10.1080/01431160110107671, 2002.

Baghdadi, N., Holah, N., and Zribi, M.: Soil moisture estimation using multi-incidence and multi-polarization ASAR data, Int. J. Remote Sens., 27, 1907-1920, doi:10.1080/01431160500239032, 2006.

Bartalis, Z., Wagner, W., Naeimi, V., Hasenauer, S., Scipal, K., Bonekamp, H., Figa, J., and Anderson, C.: Initial soil moisture retrieval from the METOP-A Advanced Scatterometer (ASCAT), Geophys. Res. Lett., 34, L20401, doi:10.1029/2007GL031088, 2007.

Brocca, L., Hasenauer, S., Lacava, T., Melone, F., Moramarco, T., Wagner, W., Dorigo, W., Matgen, P., Martínes-Fernández, J., Llorens, P., Latron, J., Martin, C., and Bitelli, M.: Soil moisture estimation through ASCAT and AMSR-E sensors: an intercomparison and validation study across Europe, Remote Sens. Environ., 115, 3390-3408, doi:10.1016/j.rse.2011.08.003, 2011.

Dorigo, W. A., Wagner, W., Hohensinn, R., Hahn, S., Paulik, C., Xaver, A., Gruber, A., Drusch, M., Mecklenburg, S., van Oevelen, P., Robock, A., and Jackson, T.: The International Soil Moisture Network: a data hosting facility for global in situ soil moisture measurements, Hydrol. Earth Syst. Sci., 15, 1675-1698, doi:10.5194/hess-15-1675-2011, 2011.

Draper, C. S., Walker, J. P., Steinle, P. J., de Jeu, R. A. M., and Holmes, T. R. H.: An evaluation of AMSR-E derived soil moisture over Australia, Remote Sens. Environ., 113, 703-710, doi:10.1016/j.rse.2008.11.011, 2009.

Fensholt, R. and Sandholt, I.: Derivation of a shortwave infrared water stress index from MODIS near- and shortwave infrared data in a semiarid environment, Remote Sens. Environ., 87, 111121, doi:10.1016/j.rse.2003.07.002, 2003.

Gherboudi, I., Magagi, R., Berg, A. A., and Toth, B.: Soil moisture retrieval over agricultural fields from multi-polarized and multiangular RADARSAT-2 SAR data, Remote Sens. Environ., 115, 33-43, doi:10.1016/j.rse.2010.07.011, 2011.

Hamon, R. W.: Computation of direct runoff amounts from storm rainfall, in: International Association of Scientific Hydrology, 63, 52-62, Wallingford, Oxon, UK, 1963.

Jackson, T. J., Cosh, M. H., Bindlish, R., Starks, P. J., Bosch, D. D., Seyfried, M., Goodrich, D. C., Moran, M. S., and Du, J.: Validation of Advanced Microwave Scanning Radiometer soil moisture products, IEEE T. Geosci. Remote, 48, 4256-4272, 2010.

Jarvis, A., Reuter, H. I., Nelson, A., and Guevara, E.: Hole-filled seamless SRTM data V4, International Center for Tropical Agriculture (CIAT), available at: http://srtm.csi.cgiar.org, (last access: April 2011) 2008.

Kerr, Y. H., Waldteufel, P., Wigneron, J. P., Delwart, S., Cabot, F., Boutin, J., Escorihuela, M.-J., Font, J., Reul, N., Gruhier, C., Juglea, S. E., Drinkwater, M. R., Hahne, A., Martin-Neira, M., and Mecklenburg, S.: The SMOS mission: new tool for monitoring key elements of the global water cycle, P. IEEE, 98, 666-687, doi:10.1109/JPROC.2010.2043032, 2010.

Koike, T., Nakamura, Y., Kaihotsu, I., Dawa, G., Matsuura, N., Tamagawa, K., and Fuji, H.: Development of an advanced microwave scanning radiometer (AMSR-E) algorithm of soil moisture and vegetation water content, Annual Journal of Hydraulic Engineering, 48, 217-222, 2004.

Lievens, H. and Verhoest, N. E. C.: On the retrieval of soil moisture in wheat fields from L-band SAR based on water cloud modeling, the IEM and effective roughness parameters, IEEE Geosci. Remote S., 8, 740-744, doi:10.1109/LGRS.2011.2106109, 2011.

Lievens, H., Verhoest, N. E. C., De Keyser, E., Vernieuwe, H., Matgen, P., Álvarez-Mozos, J., and De Baets, B.: Effective roughness modelling as a tool for soil moisture retrieval from C- and L-band SAR, Hydrol. Earth Syst. Sci., 15, 151-162, doi:10.5194/hess-15-151-2011, 2011.

Loew, A., Ludwig, R., and Mauser, W.: Derivation of surface soil moisture from ENVISAT ASAR wide swath and image mode data in agricultural areas, IEEE T. Geosci. Remote, 44, 889-899, doi:10.1109/TGRS.2005.863858, 2006.

Mladenova, I., Lakshmi, V., Walker, J. P., Panciera, R., Wagner, W., and Doubkova, M.: Validation of the ASAR Global Monitoring Mode soil moisture product using the NAFE'05 data set, IEEE T. Geosci. Remote, 48, 2498-2508, doi:10.1109/TGRS.2010.2040746, 2010.

Moran, M. S., Hymer, D. C., Qi, J., and Sano, E. E.: Soil moisture evaluation using multi-temporal synthetic aperture radar (SAR) in semiarid rangeland, Agr. Forest Meteorol., 105, 69-80, doi:10.1016/S0168-1923(00)00189-1, 2000.

Naeimi, V., Scipal, K., Bartalis, Z., Hasenauer, S., and Wagner, W.: An improved soil moisture retrieval algorithm for ERS and METOP scatterometer observations, IEEE T. Geosci. Remote, 47, 1999-2013, doi:10.1109/TGRS.2008.2011617, 2009.

Narayan, U., Lakshmi, V., and Jackson, T. J.: High- 
resolution change estimation of soil moisture using L-band radiometer and radar observations made during the SMEX02 experiments, IEEE T. Geosci. Remote, 44, 1545-1554, doi:10.1109/TGRS.2006.871199, 2006

Njoku, E.: AMSR-E/Aqua Daily L3 Surface Soil Moisture, Interpretive Parameters, \& QC EASE-Grids V002, [01/01/200831/12/2010]. Boulder, Colorado USA: National Snow and Ice Data Center, Digital media, updated daily, 2008.

Njoku, E. G., Jackson, T. J., Lakshmi, V., Chan, T. K., and Nghiem, S. V.: Soil moisture retrieval from AMSR-E, IEEE T. Geosci. Remote, 41, 215-229, doi:10.1109/TGRS.2002.808243, 2003.

Owe, M., de Jeu, R. A. M., and Holmes, T. R. H.: Multisensor historical climatology of satellite-derived global land surface moisture, J. Geophys. Res., 113, F01002, doi:10.1029/2007JF000769, 2008.

Pathe, C., Wagner, W., Sabel, D., Doubkova, M., and Basara, J. B.: Using ENVISAT ASAR Global Mode data for surface soil moisture retrieval over Oklahoma, USA, IEEE T. Geosci. Remote, 47, 468-480, doi:10.1109/TGRS.2008.2004711, 2009.

Pebesma, E.: Multivariable geostatistics in $\mathrm{S}$ : the gsat package, Comput. Geosci., 30, 683-691, doi:10.1016/j.cageo.2004.03.012, 2004.

Pellarin, T., Calvet, J.-C., and Wagner, W.: Evaluation of ERS scatterometer soil moisture products over a half-degree region in southwestern France, Geophys. Res. Lett., 33, L17401, doi:10.1029/2006GL027231, 2006.

Raes, D.: BUDGET: a Soil Water and Salt Balance Model, Reference manual, version 5.0., Catholic University of Leuven, 2002.

Rahman, M. M., Moran, M. S., Thoma, D. P., Bryant, R., Sano, E., Holifield Collins, C., Skirvin, S., Kershner, C., and Orr, B.: A derivation of roughness correlation length for parameterizing radar backscatter models, Int. J. Remote Sens., 28, 3995-4012, 2007.

Rahman, M. M., Moran, M. S., Thoma, D. P., Bryant, R., Holifield Collins, C. D., Jackson, T., Orr, B. J., and Tischler, M.: Mapping surface roughness and soil moisture using multi-angle radar imagery without ancillary data, Remote Sens. Environ., 112, 391-402, doi:10.1016/j.rse.2006.10.026, 2008.

Sandholt, I., Rasmussen, K., and Andersen, J.: A simple interpretation of the surface temperature/vegetation index space for assessment of surface moisture status, Remote Sens. Environ., 79, 213-224, doi:10.1016/S0034-4257(01)00274-7, 2002.

Saxton, K. E. and Rawls, W. J.: Soil water characteristic estimates by texture and organic matter for hydrologic solutions, Soil Sci. Soc. Am. J., 70, 1569-1578, doi:10.2136/sssaj2005.0117, 2006.

Saxton, K. E., Rawls, W. J., Romberger, J. S., and Papendick, R. I.: Estimating generalized soil-water characteristics from texture, Soil Sci. Soc. Am. J., 50, 1031-1036, 1986.
Sheikh, V., Visser, S., and Stroosnijder, L.: A simple model to predict soil moisture: Bridging Event and Continuous Hydrological (BEACH) modelling, Environ. Modell. Softw., 24, 542-556, doi:10.1016/j.envsoft.2008.10.005, 2009.

Shoshany, M., Svoray, T., Curran, P. J., Foody, G. M., and Perevolotsky, A.: The relationship between ERS-2 SAR backscatter and soil moisture; generalization from a humid to semi-arid transect, Int. J. Remote Sens., 21, 2337-2343, doi:10.1080/01431160050029620, 2000.

Small, D. and Schubert, A.: Guide to ASAR geocoding, RSLASAR-GC-AD, 2008.

$\mathrm{Su}, \mathrm{Z}$., Troch, P., and De Troch, F.: Remote sensing of bare surface soil moisture using EMAC/ESAR data, Int. J. Remote Sens., 18, 2105-2124, doi:10.1080/014311697217783, 1997.

Topp, G. C. and Reynolds, W. D.: Time domain reflectometry: a seminal technique for measuring mass and energy in soil, Soil Till. Res., 47, 125-132, 1998.

Wagner, W., Lemoine, G., Borgeaud, M., and Rott, H.: A study of vegetation cover effects on ERS scatterometer data, IEEE T. Geosci. Remote, 37, 938-948, doi:10.1109/36.752212, 1999a.

Wagner, W., Noll, J., Borgeaud, M., and Rott, H.: Monitoring soil moisture over the Canadian Prairies with the ERS Scatterometer, IEEE T. Geosci. Remote, 37, 206-216, doi:10.1109/36.739155, 1999b.

Wagner, W., Pathe, C., Doubkova, M., Sabel, D., Bartsch, A., Hasenauer, S., Blöschl, G., Scipal, K., Martińez-Fernández, J., and Löw, A.: Temporal stability of soil moisture and radar backscatter observed by the Advanced Synthetic Aperture Radar (ASAR), Sensors, 8, 1174-1197, doi:10.3390/s8021174, 2008.

Wagner, W., Sabel, D., Doubkova, M., Bartsch, A., and Pathe, C.: The potential of Sentinel-1 for monitoring soil moisture with high spatial resolution at global scale, in: Symposium of Earth Observation and Water Cycle Science, 2009.

Wickel, A. J., Jackson, T. J., and Wood, E. F.: Multitemporal monitoring of soil moisture with RADARSAT SAR during the 1997 Southern Great Plains hydrology experiment, Int. J. Remote Sens., 22, 1571-1583, doi:10.1080/01431160120291, 2001.

Zribi, M., Baghdadi, N., Holah, N., and Fafin, O.: New methodology for soil surface moisture estimation and its application to ENVISAT-ASAR multi-incidence data inversion, Remote Sens. Environ., 96, 485-496, doi:10.1016/j.rse.2005.04.005, 2005.

Zribi, M., Saux-Picart, S., André, C., Descroix, L., Ottlé, C., and Kallel, A.: Soil moisture mapping based on ASAR/ENVISAT radar data over a Sahelian region, Int. J. Remote Sens., 28, 3547 3565, 2007. 